\title{
PRECIPITATION TRENDS IN THE CANARY ISLANDS
}

\author{
RICARDO GARCÍA-HERRERA, ${ }^{\mathrm{a}, *}$ DAVID GALLEGO, ${ }^{\mathrm{a}}$ EMILIANO HERNÁNDEZ, ${ }^{\mathrm{a}}$ LUIS GIMENO, ${ }^{\mathrm{b}}$ PEDRO RIBERA ${ }^{\mathrm{c}}$ and \\ NATALIA CALVO ${ }^{\mathrm{a}}$ \\ a Universidad Complutense de Madrid, Madrid, Spain \\ ${ }^{\mathrm{b}}$ Universidad de Vigo, Vigo, Spain \\ c Universidad Pablo de Olavide, Spain
}

Received 22 April 2002

Revised 4 October 2002

Accepted 6 October 2002

\begin{abstract}
A strong decreasing trend in the Canary Islands' precipitation is detected by studying daily rainfall time series for the second half of the 20th century. An analysis of the extreme events shows that this trend is due mainly to a decrease in the upper percentiles of the precipitation distribution. The results suggest that local factors play a fundamental role on extreme event behaviour. Copyright (c) 2003 Royal Meteorological Society.
\end{abstract}

KEY WORDS: Canary Islands; trend analysis; precipitation; climate extremes

\section{INTRODUCTION}

The Canary Islands are located in the subtropical North Atlantic, from $27^{\circ} 37^{\prime}$ to $29^{\circ} 25^{\prime} \mathrm{N}$ and from $18^{\circ} 10^{\prime}$ to $13^{\circ} 20^{\prime} \mathrm{W}$. The climatology of the Canary Islands is determined both by their geographical location and orography. The proximity to the Azores high makes the Canaries' climate dry and stable. Nevertheless, the steep orography, with altitudes up to $3700 \mathrm{~m}$, acts as a triggering factor for atmospheric instability. The Canarian Archipelago is, with the exception of the two eastern islands, much wetter than usual for its latitude, providing a signal/noise ratio for precipitation hardly found in the subtropical North Atlantic environment. The wet season spans from October to April. Both the dominant average winds, blowing from the northwest, and the average storm track lead to higher precipitation in the northern side of the five western islands. Almost $80 \%$ of the precipitation is related to atmospheric disturbances, such as Atlantic low-pressure systems or cold air invasions in the upper troposphere, although the percentage varies between islands (García et al., 2001). This relationship between precipitation and North Atlantic synoptic structure makes the North Atlantic oscillation (NAO) an important source of variability for Canarian precipitation during winter. The aim of this paper is to study the precipitation trends in the Canary Islands, with special attention to the changes in the extreme precipitation events.

\section{DATA AND METHOD}

Daily precipitation data from eight stations along the Canarian Archipelago were selected from the Spanish Meteorological Institute by considering quality and length (see Table I and Figure 1). Time coverage varies

* Correspondence to: Ricardo García-Herrera, Departamento de Fisica de la Tierra II, Facultad de Ciencias Fisicas, Universidad Complutense de Madrid, Avda. Complutense s/n, 28040 Madrid, Spain; e-mail: rgarcia@6000aire.fis.ucm.es 
Table I. Time coverage, average annual precipitation and average precipitation corresponding to the 20th category events

\begin{tabular}{llclc}
\hline Island & Station & Time coverage & \multicolumn{2}{c}{ Average precipitation (mm) } \\
\cline { 4 - 5 } & & & Annual & 20th category \\
\hline La Palma & LP & $1971-98$ & 294.2 & 44.7 \\
Tenerife & TE1 & $1948-98$ & 371.7 & 70.0 \\
& TE2 & $1951-98$ & 606.4 & 44.2 \\
& TE3 & $1943-98$ & 235.4 & 34.7 \\
Gran Canaria & GC1 & $1950-94$ & 124.1 & 19.8 \\
& GC2 & $1951-98$ & 133.0 & 33.6 \\
Fuerteventura & FU & $1970-98$ & 97.9 & 31.6 \\
Lanzarote & LA & $1973-98$ & 99.9 & 20.2 \\
\hline
\end{tabular}

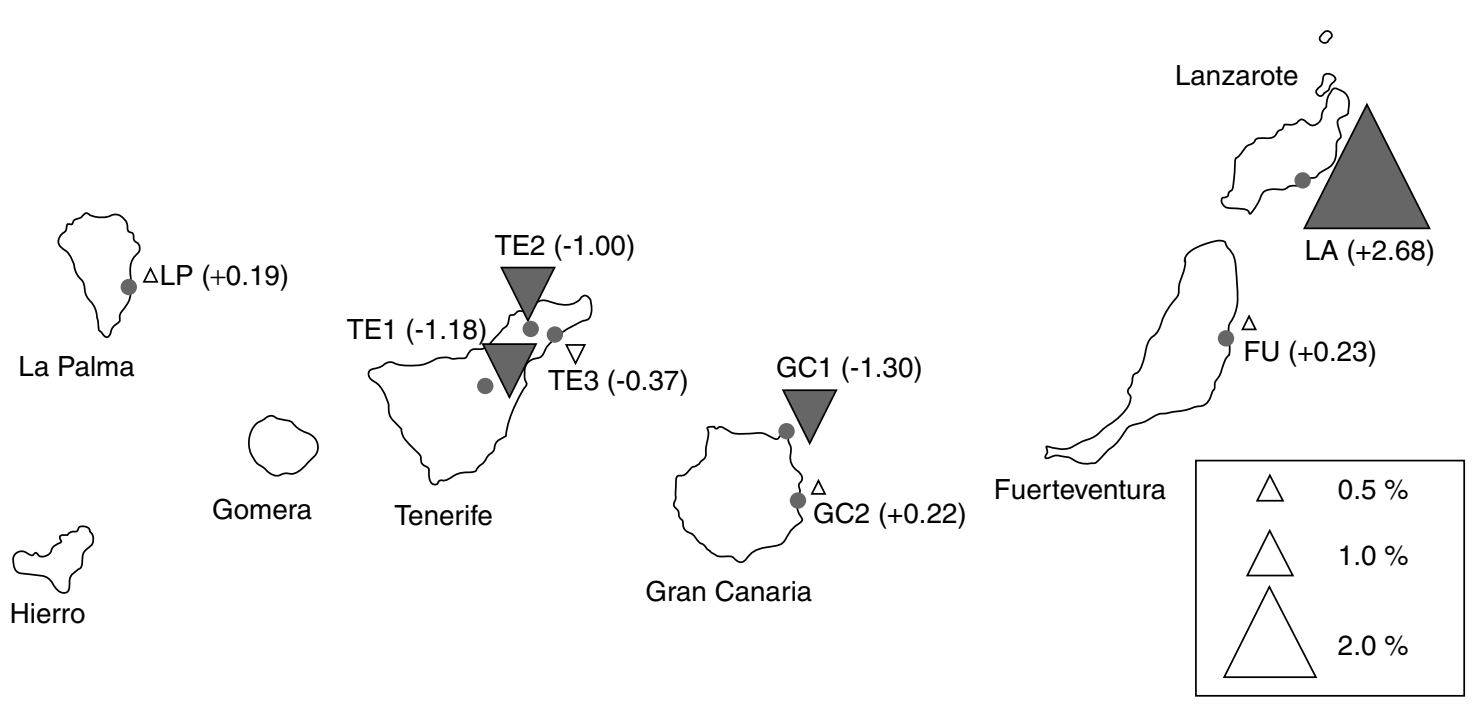

Figure 1. Locations of the eight precipitation stations used and global precipitation trend expressed as a percentage of the annual average over the study period. Significant trends are shaded

between stations. The two main islands (Tenerife and Gran Canaria) provide data for the whole second half of the 20th century. The smaller islands do not provide reliable records prior to 1970. Nevertheless, a station in La Palma and two in Fuerteventura and Lanzarote have been included in order to represent the rainiest and the driest of the islands respectively.

\subsection{Data treatment}

The raw time series exhibit some missing data that must be filled to avoid introducing bias when computing precipitation trends. Binomial and gamma distributions were fitted on a monthly basis to each station's daily data. When missing data were found, the precipitation occurrence was estimated by a random number generator adjusted to the empirical probability of precipitation for each month and station. If the result was a precipitation day, the precipitation amount was estimated through an empirically adjusted gamma distribution (Karl et al., 1995). The distribution parameters were considered time independent; thus, no artificial trends are expected due to the filling method. 


\subsection{Precipitation trends}

The methodology used for the computation of the trends closely follows that of Karl and Knight (1998). Each precipitation series was split into 20 categories. The first one groups the percentiles one to five (i.e. the smallest precipitation events). The second one, groups percentiles six to ten, and so on. Finally, the 20th category represents the highest events (percentiles 96 to 100; to be referred to as extreme events from now on). Annual time series of precipitation frequency and amount were computed for each station and category.

For each category, three annual trends were computed:

1. The global precipitation trend $b$, which reveals the total variation in precipitation for each category (measured in $\mathrm{mm} \mathrm{year}^{-1}$ ). The sum of the $b$ trends over the 20 categories is equal to the total precipitation trend.

2. The precipitation trend due exclusively to changes in the frequency of precipitation $b_{\mathrm{e}}$. This trend is computed by multiplying the trend of the precipitation frequency (measured in precipitation days year ${ }^{-1}$ ) by the average precipitation of each category (mm precipitation day ${ }^{-1}$ ).

3. The precipitation trend $b_{\mathrm{i}}$ due to changes in the intensity of precipitation of each category. This trend is simply computed by subtracting $b$ from $b_{\mathrm{e}}$.

In order to provide a direct comparison between isles, the trends were expressed as the percentage change over the average precipitation of each station. The statistical significance of the trend was assessed by means of a 10000 trials Monte Carlo test. For every trial, each precipitation series was randomly disordered, the new trends computed and the results compared with the real value. The statistical significance level was set to $90 \%$.

\section{RESULTS}

The semi-arid character of most of the Canarian group can be seen in Table I. The two driest islands (Lanzarote and Fuerteventura) exhibit annual precipitation lower than $100 \mathrm{~mm}$, whereas the rest of the archipelago shows annual precipitation totals between $124.1 \mathrm{~mm}$ (GC1) and $371.7 \mathrm{~mm}$ (TE1). The exception is TE2, with more than $600 \mathrm{~mm}$ year ${ }^{-1}$ due both to its location on the northern side of Tenerife, exposed to the dominant winds, and its altitude $(617 \mathrm{~m})$.

Figure 1 shows the total precipitation trends. The two main islands (Tenerife and Gran Canaria) exhibit strong and significant decreasing trends over their northern sides, with values between $-1.30 \%$ for GC1 and $-1.00 \%$ for TE2. The stations located over the southeastern coasts of these isles display smaller and non-significant values. The relevance of these results must be pointed out. For instance, a decrease of $1.18 \%$ per year for the TE1 station is equivalent to a variation greater than $200 \mathrm{~mm}$ between 1948 and 1998, a precipitation amount comparable to the annual average. There are no significant trends on the single stations available over La Palma (LP) and Fuerteventura (FU), whereas Lanzarote's station (LA) exhibits an exceptional positive trend of $+2.68 \%$.

Figure 2 shows four examples of the trend distribution in terms of the 20 precipitation categories. TE2 and GC1 (Figure 2(a) and (c)) and TE1 (not shown) exhibit the common behaviour of the stations characterized by a large and significant global negative trend. In the case of TE3, despite a smaller global negative trend $(-0.37 \%)$, the precipitation of the most severe events has decreased significantly (Figure 2(b)). The large trend observed in Lanzarote (Figure 2(d)) now appears as the result of the cumulative effect of changes in the upper categories 18, 19 and 20. The rest of the stations (LP, GC2 and FU, not shown) exhibit similar patterns, but with lower and non-significant values. The principal common characteristic is the concentration of the trend almost exclusively within the category corresponding to the most extreme events. The numerical value of the average daily precipitation corresponding to these extremes can be seen in Table I.

An analysis in terms of changes in the intensity and frequency (Figure $2, b_{\mathrm{e}}$ and $b_{\mathrm{i}}$ graphs) shows that, in general, the trends in categories lower than 20 are the result of changes in the frequency $\left(b_{e}\right)$ rather than intensity of precipitation $\left(b_{\mathrm{i}}\right)$ (Figure 2(c) or (d) is a good example). On the other hand, changes in the 20th 
(a) TE2

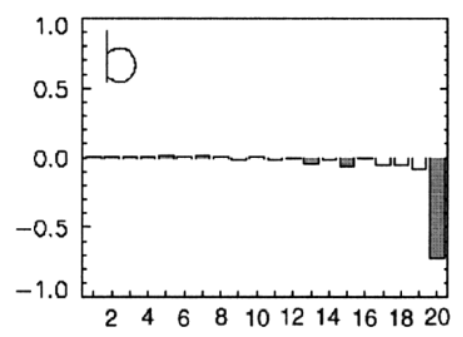

\section{(b) TE3}

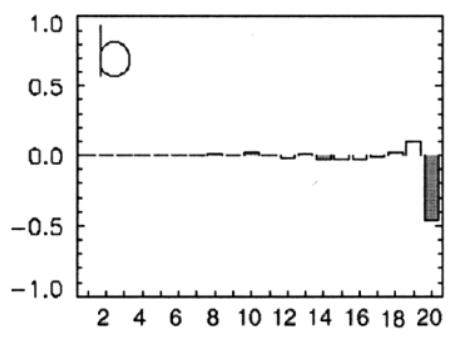

(c) GC1

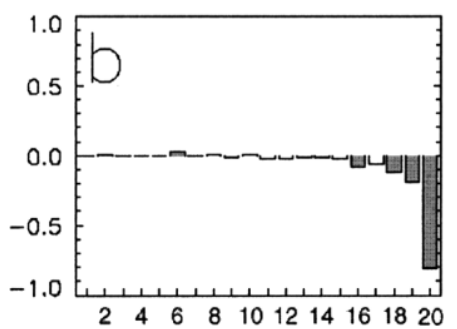

(d) LA
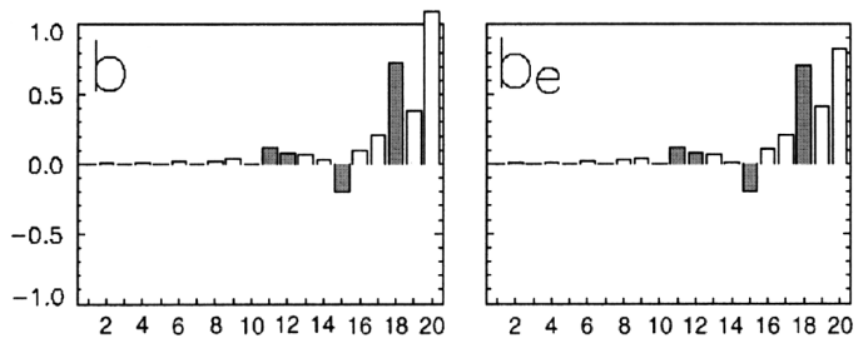
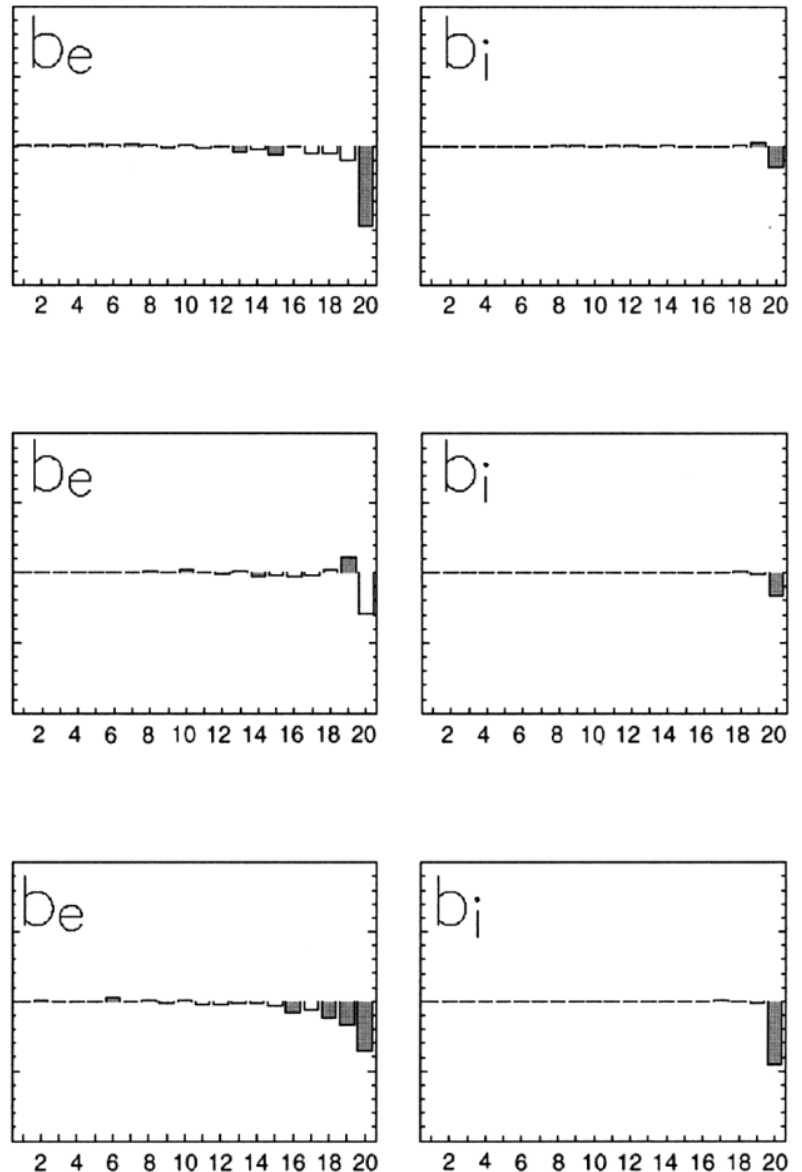

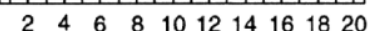

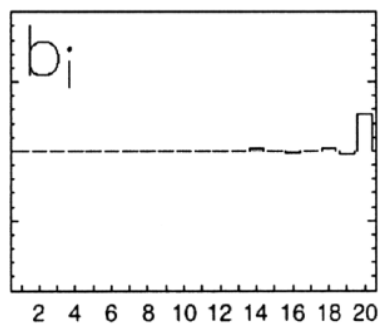

Figure 2. Trends (expressed as a percentage of the annual average over the study period) for the 20 categories of precipitation defined by five percentile intervals for the stations TE2, TE3, GC1 and LA. Values for the first category correspond to the trend in precipitation for the first to fifth percentiles, the second category to the sixth to tenth percentiles, etc. $b, b_{\mathrm{e}}$ and $b_{\mathrm{i}}$ graphs represent respectively the total, the frequency and the intensity contributions to the trend. Vertical scale from -1 to $+1 \%$. The sum of the $20 b$ values is equal to the global trend in Figure 1. Significant trends based on a 10000 trials Monte Carlo test are shaded

category are, in general, shared by simultaneous changes in the frequency and intensity of the extreme events, with greater contributions in the frequency.

In a previous study by García et al. (2001), the NAO influence over Canarian precipitation was clearly established, with greater precipitation during NAO negative years. To a lesser extent, the influence of the 
strong ENSO events has also been pointed out (Gallego et al., 2001). The possible modulation effect by these oscillations in the distribution of extreme precipitation days has been investigated by regressing the precipitation (Bevington and Robinson, 1992) against the NAO index (Jones et al., 1997) and southern oscillation (SO) index (Ropelewski and Jones, 1987). The resulting trends were independent of the SO index. For the NAO, very slight and non-significant changes were evident. A maximum of $10 \%$ (TE3) of the global trend can be attributed to the linear contribution of the NAO.

Finally, an analysis of the synoptic configurations leading to extreme precipitation events was performed based on the objective scheme developed in García et al. (2001) for the 1955-98 NCEP-NCAR reanalysis data (Kalnay et al., 1996). On average, $66 \%$ of the extreme events were related to the presence of cold air in the mid-troposphere $\left(500 \mathrm{hPa}\right.$ level). A significant decrease $\left(1.2 \mathrm{gpm} \mathrm{year}^{-1}, p<0.01\right)$ in the depth of these cold air centres at $500 \mathrm{hPa}$ affecting the Canary Islands was found in the period covered by the reanalysis. On the other hand, only about $18 \%$ of the extreme precipitation is due to an Atlantic low-pressure system, $2 \%$ is due to advection of cold air at the surface and the remaining $14 \%$ did not correspond to any of the synoptic configurations tested.

\section{CONCLUSIONS}

In this paper, the importance of severe precipitation events when characterizing rainfall changes in the Canary Islands has been illustrated. Across Tenerife and northern Gran Canaria, a strong decreasing trend has been detected during the whole second half of the 20th century. This is mainly due to a noticeable drop in the frequency of precipitation of the most intense events, although a significant decrease in their intensity has also been found. In the rest of the archipelago, lower non-significant (or even positive, as in the LA case) global trends have been obtained. In all cases, extreme events play a fundamental role in explaining the precipitation trends found. In order to check the importance of the different study periods at each station, the same study was carried out for different time periods (including the common period 1973-94). With the exception of TE1 (and only towards the end of the series), the rest of the trends in the longer series of Tenerife and Gran Canaria are shown to be stable.

To understand the differences found between stations, it is necessary to consider the mechanisms leading to extreme precipitation in the Canaries. The main generator of extreme precipitation in the islands is the presence of cold air in the mid-troposphere. Atlantic lows, though very important for annual precipitation, especially during winter, play a secondary role, being responsible for less than $18 \%$ of the extreme precipitation days. The local effect of the orography enhanced by the presence of cold air in upper levels is essential to the development of thermodynamic instability and extreme precipitation. The fact that the stations located over the northern side of the higher altitude islands (the area where the triggering effect of the orography is more important) are those displaying the most consistent negative trends (along with the decrease in the depth of the cold air centres during the period 1955-98) supports this idea. In contrast, the three stations located along their southern coasts show very small values (LP, TE3 and GC2).

The analysis over the series in Lanzarote, Fuerteventura and La Palma was performed to illustrate the importance of the extreme events on the precipitation trends across the entire archipelago. Nevertheless, the results, and especially the comparison with the long series of Tenerife and Gran Canaria, must be interpreted cautiously for two reasons:

1. The absence of a common period of study, due to the lack of long daily precipitation series for these islands.

2. The low precipitation rates in Lanzarote and Fuerteventura due to their low relief. This leads to an inherent instability in the trends that are not detected in the rest of the time series. In FU and LA, one or two strong events in a year can change the trend sign for the 20th category. Even the division of precipitation according to its intensity is problematic, since very few events fall in each category. For example, when the original initial year of the FU time series (1970) is changed to 1973 in order to provide direct comparison with LA, the original decreasing trend is almost lost. This is, in fact, the ultimate reason explaining why the trends in the upper categories at that station (Figure 2(d)) are not significant. 
Despite the well-established influence of the NAO over Canarian precipitation, the trends show little dependence with this oscillation. There are two reasons for the absence of an NAO signal. First, the main reason for the relation between precipitation and the NAO is the effect of Atlantic lows (García et al., 2001), a type of system poorly related to extreme precipitation. Second, the NAO-precipitation relationship is found exclusively during winter. Although this is the rainy season in the Canaries, a considerable part of precipitation, and extreme precipitation days is due to the development of convective cells, which occurs during autumn and spring, a period when no relation with the NAO is found.

A number of changes in the distribution of extreme precipitation events have been observed in several parts of the world during the second half of the 20th century, often seen as one of the most noticeable effects of climatic change (Easterling et al., 2000). The USA has suffered a significant increase in precipitation due to the upper tail of the precipitation distribution (Karl et al., 1996; Karl and Knight, 1998). Strong wintertime precipitation events seem to have increased in the UK (Osborn et al., 2000) and the southeast Mediterranean coast (Goodess and Jones, 2002). Nevertheless, a number of different studies have stressed the different behaviour of precipitation trends depending on location. For example, over Australia there has been a decrease in both rain and heavy events (Suppiah and Hennessy, 1998). In the Iberian Peninsula, a positive tendency in the frequency of low precipitation days has been detected (Goodess and Jones, 2002), and a strong link between changes in some Atlantic synoptic patterns and extreme precipitation events over Portugal has also been found (Trigo and DaCamara, 2000). Over Canada, precipitation trends have been linked to increases in the number of small to moderate events (Akinremi et al., 1999; Zhang et al., 2001), whereas throughout the Sahel, a decrease both in annual rainfall and in heavy precipitation days has been found (Tarhule and Woo, 1998). Therefore, it seems clear that local factors play a fundamental role when studying changes in precipitation. Our results suggest that this influence can be significant even in such small areas as the Canarian Archipelago.

\section{ACKNOWLEDGEMENTS}

This study is supported by the Spanish Comision Interministerial de Ciencia y Tecnologia under grant CLI980649. The Spanish Instituto Nacional de Meteorología provided the data for this study. The authors wish to thank the two anonymous referees for their useful comments, which contributed to improving the quality and presentation of this work.

\section{REFERENCES}

Akinremi O, McGinn S, Cutforth H. 1999. Precipitation trends on the Canadian prairies. Journal of Climate 12: $2996-3003$.

Bevington PR, Robinson DK. 1992. Data Reduction and Error Analysis for the Physical Sciences. McGraw Hill: USA.

Easterling DR, Meehl GA, Parmesan C, Changnon SA, Karl TR, Mearns LO. 2000. Climate extremes: observations, modeling and impacts. Science 289: 2068-2074.

Gallego D, García R, Hernandez E, Gimeno L, Ribera P. 2001. An ENSO signal in the North Atlantic subtropical area. Geophysical Research Letters 28(15): 2939-2942.

García R, Gallego D, Hernandez E, Gimeno L, Ribera P. 2001. Influence of the North Atlantic oscillation on the Canary Islands precipitation. Journal of Climate 14: 3889-3903.

Goodess CM, Jones PD. 2002. Links between circulation and changes in the characteristics of Iberian rainfall. International Journal of Climatology 22: 1593-1615.

Jones PD, Jonsson T, Wheeler D. 1997. Extension to the North Atlantic oscillation using early instrumental pressure observations from Gibraltar and south-west Iceland. International Journal of Climatology 17: 1433-1450.

Kalnay E, Kanamitsu M, Kistler R, Collins W, Deaven D, Gandin L, Iredell M, Saha S, Woollen J, Zhu Y, Chelliah M, Ebisuzaki W, Higgins W, Janowiak J, Mo KC, Ropelewski C, Wang J, Leetmaa A, Reynolds R, Jenne R, Joseph D. 1996. The NCEP/NCAR 40-year reanalysis project. Bulletin of the American Meteorological Society 77: 437-471.

Karl TR, Knight RW. 1998. Secular trends of precipitation amount, frequency and intensity in the Unites States. Bulletin of the American Meteorological Society 79(2): 231-241.

Karl TR, Knight RW, Plummer N. 1995. Trends in high-frequency climate variability in the twentieth century. Nature 377: $217-220$.

Karl TR, Knight RW, Easterling D, Quayle R. 1996. Indices of climate change for the United States. Bulletin of the American Meteorological Society 77: 279-292.

Osborn TJ, Hulme M, Jones PD, Basnett T. 2000. Observed trends in the daily intensity of United Kingdom precipitation. International Journal of Climatology 20: 347-364.

Ropelewski CF, Jones PD. 1987. An extension of the Tahiti-Darwin southern oscillation index. Monthly Weather Review 115: $2161-2165$.

Suppiah R, Hennessy KJ. 1998. Trends in total rainfall, heavy rain events and number of dry days in Australia. International Journal of Climatology 18: 1141-1164. 
Tarhule A, Woo M-K. 1998. Changes in rainfall characteristics in northern Nigeria. International Journal of Climatology 18: $1261-1271$.

Trigo R, DaCamara C. 2000. Circulation weather types and their influence on the precipitation regime in Portugal. International Journal of Climatology 20: 1559-1581.

Zhang X Hogg WD, Mekis E. 2001. Spatial and temporal characteristics of heavy precipitation events over Canada. Journal of Climate 14: $1923-1936$. 